\title{
Ground Support Resources Allocation Modeling and Optimizing for Multiple Types of Military Aircraft
}

\author{
Fuqin Yang ${ }^{1,2}$, Hongwei Liu ${ }^{1, *}$ and Mingzhu $\mathrm{Zhu}^{1}$

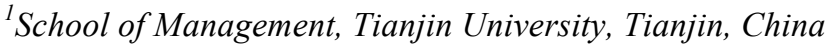 \\ ${ }^{2}$ Department of Military Logistics, Military Transportation University, Tianjin, China
}

\begin{abstract}
The co-operation of multiple types of military aircraft has become one of the basic features in air combats. In order to improve comprehensive support capability, how to optimize the resources distribution of ground support equipment is an important content of the air force stations modernization construction. The uneconomic and unreasonable reasons of allocation approach are analyzed based on the actual situation of allocating ground support resources for multiple types of military aircraft. The conceptual model and the requirement model of the ground support processes are given according to the different needs of support requirement for different types of military aircraft, this makes preparation for simulation and optimization models. The support resources strategies are developed in the simulation model, especially when there are two or more types of support activities arranged to be performed in any order with Arena software. The ground support resources allocation is optimized using intelligence-optimized algorithms in the optimizing models. The optimization results show that simulation model and optimum approach can improve the efficiency of ground support activities of multiple types of military aircraft and can increase the effectiveness of ground support resources scheduling in the support processes.
\end{abstract}

Keywords: Turnaround time, Support resource, Multiple types of military aircraft.

\section{INTRODUCTION}

With the wide application of information in the field of aviation weapon equipment and the increasingly complicated battlefield environment, the probability of a single type of aircraft to complete the task is smaller and smaller. In the information-based warfare, the victory depends on the concerted action of multiple types of aircraft and various armed forces [1]. The co-operation of multiple types of military aircraft (MTMA) has become one of the basic features in air combats. Providing supply for MTMA, the air force comprehensive stations have become the main base for offensive and defensive forces.

In order to meet requirements for MTMA in modern warfare, optimizing the resources distribution of ground support equipment and improving comprehensive support capability have become an important part of the efforts to modernize air force stations [2-5].

Ground support activities of military aircraft at an airport include a series of support services to make the aircraft take off in time such as preflight check, supplying various oil and gases, hanging drop tank and munitions. From an aircraft point of view, ground support processes begin with the military aircraft touching down and taxiing into the station,

*Address correspondence to this author at the No.92, Weijin Road, Nankai District, Tianjin, China. Postcard: 300072; Tel: 13388033735;

E-mail: hw_liu999@tju.edu.cn continue with a sequence of support activities and end with taxiing out to the runway and being ready for take-off.

Turnaround time, which is related to the quantity of various ground support resources in use, is a key parameter for evaluating operational readiness of military aircraft [6-7]. In order to improve the sortie generation of military aircraft to effectively enhance combat capability, shortening turnaround time has become an important goal in the design of military aircraft and scheduling of support resources at an airport in the ALS [8] model and in the logistics composite model (LCOM) [9].

Since the ground support processes are complex discreteevent dynamic systems, simulation is an appropriate method for support system performance estimation. With Arena, a SIMAN language based software developed by Systems Modeling and acquired by Rockwell Automation in 2000, the simulation models for vehicle scheduling in the ground support process have been built for a single type of military aircraft [10], the relationship between turnaround time for a single type of military aircraft and allocation of support resources has been discussed, and the allocation efficiency of support resources before and after optimization has been compared and analyzed $[11,12]$.

However, how to allocate ground support resources properly for MTMA has become an important issue that must be solved in making logistics plan for the logistical department, which has not been discussed in above 


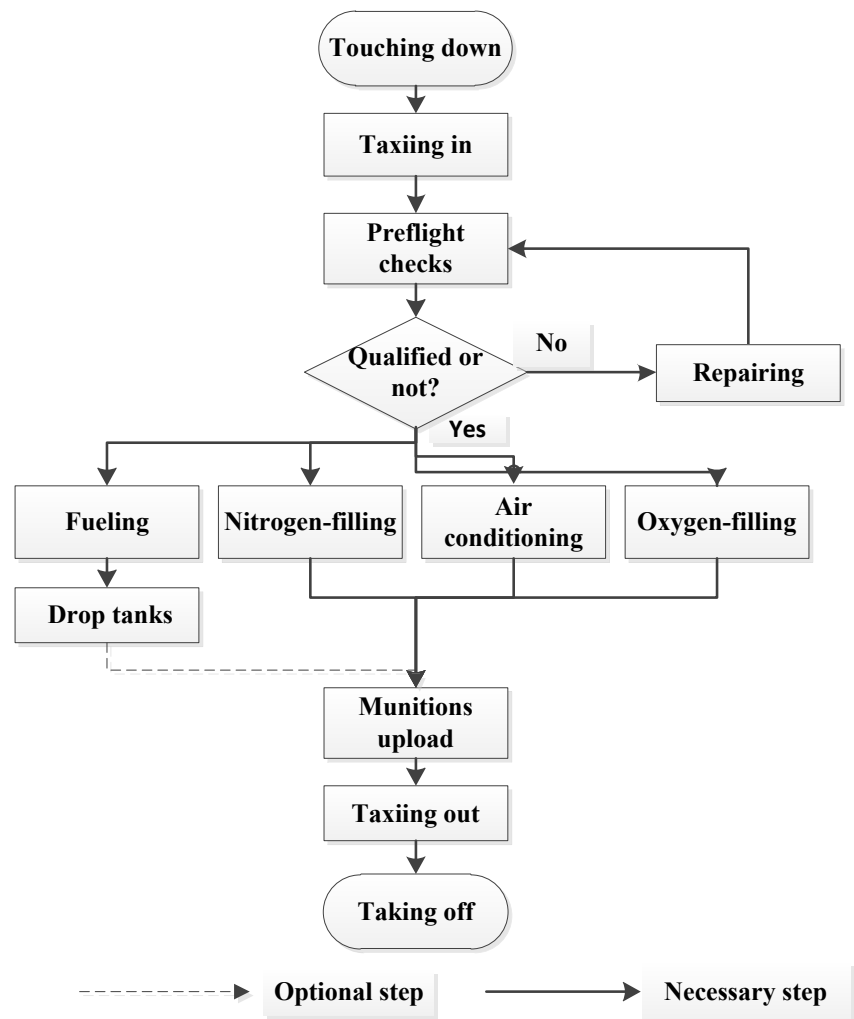

Fig. (1). Conceptual model of the ground support processes.

literatures. In practice, the general approach is to allocate an integer multiple of ground support resources based on the types of military aircraft needed in the war. That is, allocate double ground support resources for two types of military aircraft and triple for three types of military aircraft [13]. This allocation approach is usually uneconomic and unreasonable. One reason is that the flight outfield is rather limited at an airport and would be difficult to accommodate too many ground support resources, which may lead to unnecessary flight delay and loss, for example, the collisions among support equipment and aircraft. The second reason is that the processes of support activities are different for different types of military aircraft. Some support activities must be performed sequentially while the others may be done in any order. Another reason is that there are many common ground support resources which can be used for various aircraft, although some equipment is specialized. Therefore, allocating each type of support resources many times may be unnecessary. The enumeration method has been adopted to optimize allocation of support resources tentatively [14], but it is less efficient and its solution is not necessarily ideal or optimized.

In this paper, a modeling and optimizing approach is presented to address the problem of ground support resources allocation for MTMA. The modeling practice of multiple support processes which can be performed in any order is discussed. And the simulation and optimizing model of the ground support processes of military aircraft are completed using Arena software and Opt Quest tool, respectively [15].

\section{DESCRIPTION OF THE GROUND SUPPORT PROCESSES}

From the time of touching down to the time of taking off, ground support processes of MTMA are quite complex and comprise a sequence of support activities which include preflight check (scheduled maintenance), repair (unscheduled maintenance), refueling, oxygen-filling, nitrogen-filling, air conditioning, drop tank and munitions upload. It should be noted that the ground support processes vary according to the turnaround tasks, the types of military aircraft and different operators (ground handlers). While some support activities cannot start before others end (sequential activities), there are some support activities that can be done in any order (or concurrent activities). For example, munitions upload cannot start before all the other support activities have ended for safety reasons to some military aircraft. It is strictly forbidden to refuel the aircraft during oxygen-filling to some type of military aircraft. On the other hand, aircraft refueling, nitrogen-filling and air conditioning can be performed in any order. And it's worth noting that the three stages of oxygenfilling, nitrogen-filling and air conditioning are arranged in no particular order, the aircraft can select any one to wait for being serviced according to the minimum number or time of queue in the service station. Furthermore, if one type of aircraft does not need some support activities, then the corresponding device is not needed. For instance, some types of aircraft do not need drop tanks in performing the task.

Based on queuing theory, the turnaround time of military aircraft is the response time, also known as the sojourn time, which is the total time that a military aircraft spends in the queuing system. The waiting time is the time that a military aircraft spends in a queue waiting to be serviced (supported) due to lack of enough support resources such as vehicle, ground handlers, space and runways. Therefore, the turnaround time is equal to the waiting time and service time. Usually, the ground support processes are performed according to flight logistics support schedule. In order to not only meet the safety requirements but also reduce the turnaround time as much as possible, the resources allocation efficiency of support activities has to be optimized.

In this study, the research objective will be focused on determining the optimal quantity of ground support resources for MTMA with minimum average turnaround time.

A conceptual model of the ground support processes has been developed for MTMA, as shown in Fig. (1), which includes all the support activities simulated. The broken connecting lines represent activities being optional to aircraft and the solid connecting lines represent activities being necessary to aircraft in ground support processes. All the support activities must be performed in the order shown by the arrows. If there is no arrow connecting two activities, this means that they are independent of each other and can be performed in any order. For instance, in Fig. (1), oxygenfilling, nitrogen-filling and air conditioning can be performed in any order, although in the Arena simulation model (as well as in reality), these support activities may be in the order depending on resource availability. 


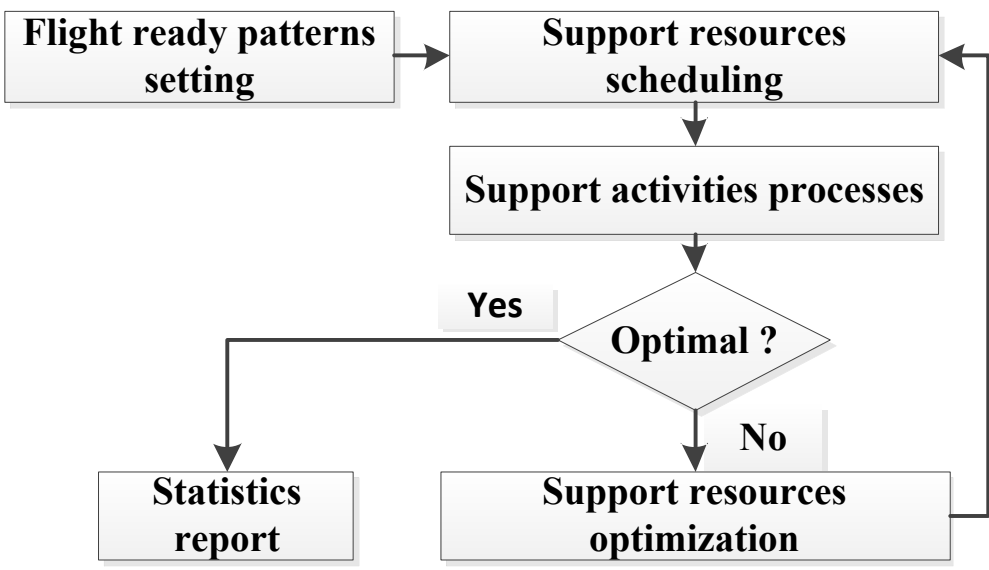

Fig. (2). Simulation model of support resources scheduling.

Compared with the actual situation, the conceptual model is somewhat simplified:

(1) In the model, refueling and oxygen-filling can be performed in any order, which is not the case for some types of military aircraft in reality.

(2) If aircraft is not qualified during preflight check, it is not always repairable in reality. In this paper, we assume that the malfunction of military aircraft can always be repaired in time.

(3) The service time of one support resource may be different for each type of military aircraft in practice, but we assume that there are no differences between different types of military aircraft.

(4) The space for aircraft waiting in line may be limited in reality. In this paper, we assume the waiting area is large enough to accommodate all of the aircraft between the support positions.

(5) Different types of military aircraft may need different types of ground support resources in reality, but we suppose that the ground support resources are common.

\section{REQUIREMENT AND SIMULATIOM MODEL OF THE GROUND SUPPORT PROCESSES}

\subsection{The Requirement Model}

The length of turnaround time that military aircraft spend at an airport depends on the flight missions, flight pattern, airport capacity, aircraft types, aircraft number and ground support resources (including all equipment and maintenance crews) [12], which are rather limited in the battle. The service times spent on various support activities are uncontrollable variables and the behaviors of these variables are uncertain. Therefore, probability distributions need be specified in order to carry out a random input simulation.

As mentioned, the average turnaround time of one military aircraft, $\operatorname{Tj}(\mathrm{x})$, is equal to the waiting time and service time and is calculated by formula (1):

$T_{j}(X)=T_{j s}(X)+T_{j w}(X)$
Where, $j$ is the type of aircraft, the vector $X=\left(x_{1}, x_{2}, \ldots, x_{n}\right)$ , $x_{i}$ is the amount of $i$ th type of support resources, $i=(1$, $2, \ldots, n), i$ is the $n$th type of support resources. $T_{j s}(X)$ means average service time (support time) that one of the $j^{\text {th }}$ type military aircraft undertakes the various types of ground support activities. As before, $T_{j s}(X)$ is in relation with the aircraft type and flight missions, when the aircraft type and flight missions are given, $T_{j s}(X)$ becomes a constant and its theoretical distribution can be fitted according to historical data. $T_{j w}(X)$ means average wait time that one of the $j^{\text {th }}$ type military aircraft spends on the waiting area while the support resources are not available when the aircraft arrives. If each type of support resources is enough and has idle support resources when the aircraft arrives, $T_{j w}(X)$ will be reduced to minimum 0 . To optimize the average turnaround time of MTMA, average wait time of one military aircraft should be minimized at each support activity. So the minimizing $T_{j w}(X)$ becomes the optimization objective. At the same time, to ensure that the military aircraft have enough space to touch down after accomplishing their missions, the average turnaround time $T_{j}(x)$, corresponding to the entity's average total time in Arena, should be less than the inter-arrival times $T_{i j}$ which is a constant according to the fight plan.

The requirement model is shown as formula (2) (3) (4):

$\min \sum_{j=1}^{k} T_{j w}(X)$

s.t. $0 \leq x_{i} \leq m,(i=1,2, \cdots, n)$

$T_{j}(X) \leq T_{i j}(j=1,2, \cdots, k)$

Where, $T_{i j}$ is the inter-arrival times between two arrivals of $j$ th type of aircraft.

\subsection{The Simulation and Optimization Model}

The simulation model of support resources scheduling consists of five parts: flight ready patterns setting (aircraft touching down and assigning), support resources scheduling, support process, support resources optimization and statistics report, as shown in Fig. (2). 


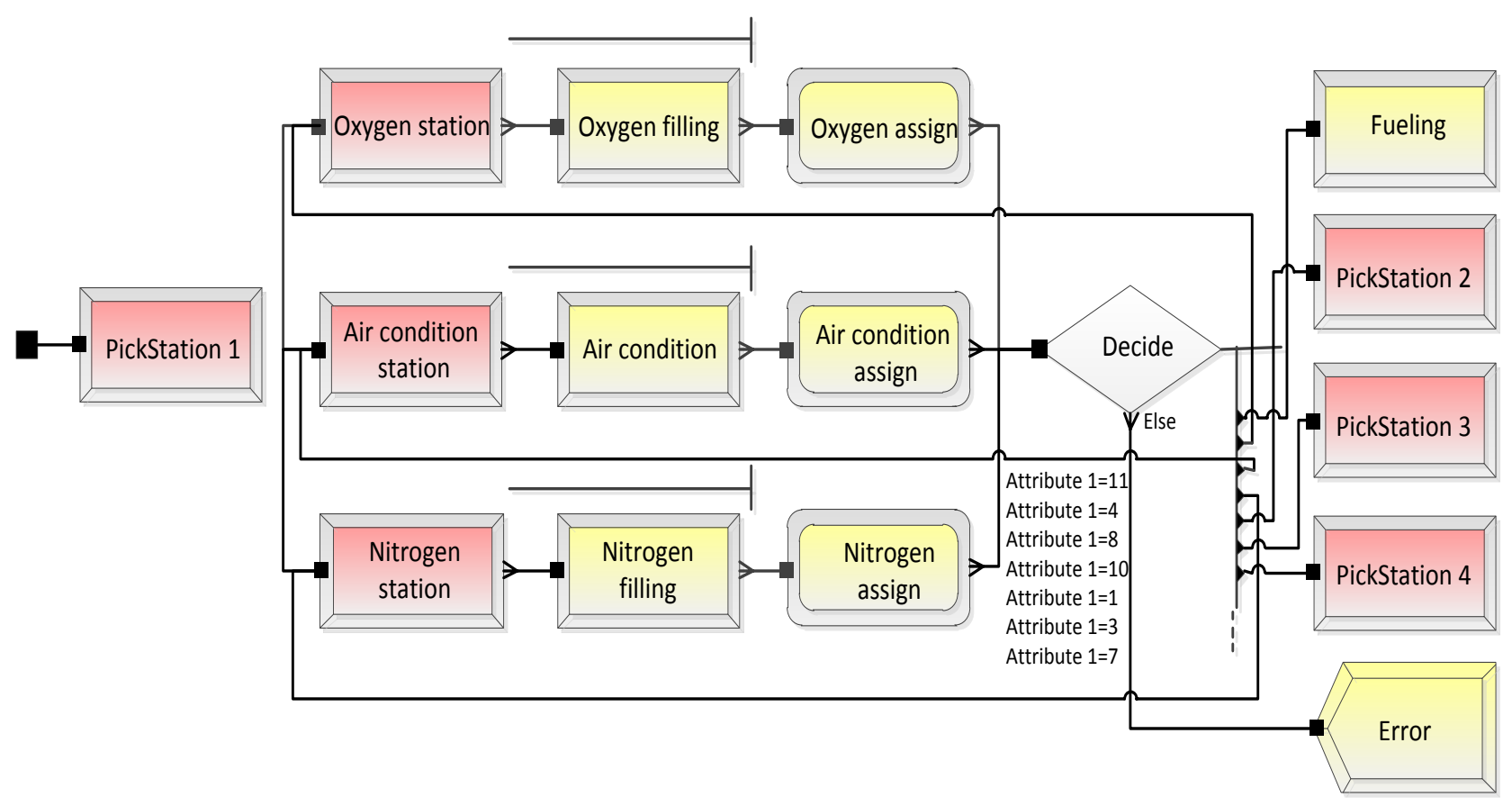

Fig. (3). Support resources scheduling process model.

The first part is flight ready patterns setting in which MTMA entities are created, the type of time probability distribution and number of aircraft entities per arrival are set, the current values of simulation clock to the arrive time and initial values of different support attributes for each type of aircraft are assigned. For example, assigning the value 0 to the aircraft attribute means that no support activities have been carried out for the aircraft. And then the aircraft entities enter the support process part.

Support resources scheduling is a core part in which various types of support resources are allocated for MTMA in the ground support process. If there are two or more types of support activities arranged to be performed in any order, the support resources strategies should offer some choices for the aircraft to make their average wait time minimum using the PickStation modules in Arena. For instance, oxygen-filling, nitrogen-filling and air conditioning are arranged to be performed in any order as shown in Fig. (1). There is a selection strategy proposed to arrange aircraft waiting in line by the minimum number in queue or by the number of resource not available. In the simulation model, if aircraft needs oxygen-filling, nitrogen-filling and air conditioning, an aircraft having completed the oxygen-filling is assigned the value 1 , one having completed the nitrogenfilling is assigned the value 3 , and one having completed the air conditioning is assigned the value 7 . So one having completed the oxygen-filling and nitrogen-filling is assigned the value 4 , one having completed the oxygen-filling and air conditioning is assigned the value 8 , one having completed the nitrogen-filling and air conditioning is assigned the value 10 , and one having completed all the three activities is assigned the value 11, as shown in Fig. (3).
The third part is support activities process in which the aircraft is serviced according to the support resources strategies. Once all the support activities have been finished, the aircraft is transferred to the support resources optimization part.

The fourth part is statistics reports of the system performance in which the simulation results for MTMA, support processes, aircraft queues and ground support resources are given and then are fed into the next part.

The support resources optimization is the last part and the other core one in which the results of simulation model are analyzed and optimized using the OptQuest, an optimization tool provided with the student version of the Arena software free of charge. Like all practical simulation optimization methods, OptQuest is also an iterative heuristic that combines the meta-heuristics of tabu search, neural networks and scatter search into a single search heuristic. Setting the parameters of support resources as control variables, the average turnaround time of one aircraft as constraints, average wait time of one aircraft as objectives, the optimum results of support resource can be obtained by OptQuest.

\section{RESULTS OF SIMULATION AND OPTIMIZATION}

The simulation model described in the previous section has been built at an airport with Arena 14.0 software environment. Weekly mean time of support activities for the period of 2014.01-2014.06 was recorded at the airport. In this case, $k=2$ means there are two types of aircraft arrivals. The first type of aircraft inter-arrival times are exponentially distributed with a mean of 65 minutes and in batches of 
Table 1. Data of theoretical distributions of aircraft support processing times.

\begin{tabular}{|c|c|c|c|c|c|c|c|c|c|}
\hline Ground Support Process & Taxiing In & Preflight Checks & Repair & Oxygen & Nitrogen & Air Conditioning & Refueling & Drop Tanks & Taxiing Out \\
\hline Distribution Type & TRIA & TRIA & TRIA & TRIA & TRIA & TRIA & TRIA & UNIF & TRIA \\
\hline Parameter (minutes) & $(1,2,3)$ & $(2,3,4)$ & $(5,8,10)$ & $(3,4,5)$ & $(3,4,5)$ & $(5,7,10)$ & $(10,15,20)$ & $(7,15)$ & $(2,3,4)$ \\
\hline
\end{tabular}

Table 2. Constraints of initial values and limits on the support resources.

\begin{tabular}{|c|c|c|c|c|c|c|c|c|}
\hline Support Resources & Taxiing Vehicles & $\begin{array}{c}\text { Preflight Checks } \\
\text { Crew }\end{array}$ & $\begin{array}{l}\text { Repair } \\
\text { Crew }\end{array}$ & Oxygen Vehicles & $\begin{array}{l}\text { Nitrogen } \\
\text { Vehicles }\end{array}$ & $\begin{array}{c}\text { Air Conditioning } \\
\text { Vehicles }\end{array}$ & $\begin{array}{c}\text { Refueling } \\
\text { Vehicles }\end{array}$ & $\begin{array}{c}\text { Drop Tanks } \\
\text { Vehicles }\end{array}$ \\
\hline Limits(min, max) & $(2,6)$ & $(1,4)$ & $(1,3)$ & $(1,6)$ & $(1,6)$ & $(1,7)$ & $(1,7)$ & $(1,4)$ \\
\hline Best Solution & 6 & 3 & 2 & 5 & 5 & 5 & 5 & 3 \\
\hline
\end{tabular}

Table 3. Various values and results of average wait time and average maximum wait time.

\begin{tabular}{|c|c|c|c|c|c|c|c|c|c|c|c|}
\hline \multicolumn{2}{|c|}{ Average Wait Time } & \multicolumn{2}{|c|}{$\begin{array}{c}\text { Average Maximum Wait } \\
\text { Time }\end{array}$} & \multicolumn{2}{|c|}{ Average Wait Time } & \multicolumn{2}{|c|}{$\begin{array}{c}\text { Average Maximum Wait } \\
\text { Time }\end{array}$} & \multicolumn{2}{|c|}{ Average Wait Time } & \multicolumn{2}{|c|}{$\begin{array}{c}\text { Average Maximum } \\
\text { Wait Time }\end{array}$} \\
\hline 1st type & 2nd type & 1 st type & 2nd type & 1st type & 2nd type & 1 st type & 2nd type & 1st type & 2nd type & 1st type & 2nd type \\
\hline
\end{tabular}

size 3. The second type of aircraft inter-arrival times are exponentially distributed with a mean of 50 minutes and in batches of size 2 . In the support process, it should be noted that the first type of aircraft needs all support activities and the second type of aircraft needs all support activities except drop tanks service.

The theoretical distributions of aircraft support processing times are fitted to a suitable distribution using Arena 14.0 input analyzer based on historical data and are given in Table 1, where TRIA and UNIF represent the triangular distribution and the uniform distribution, respectively.

The objective function is shown as $\min \sum_{j=1}^{k} T_{w j}\left(x_{i}\right)$, which means the minimum average wait time of one aircraft in the buffer before every support activities. The constraints of initial values and limits on the ground support resources are given in Table 2 .

The constraint conditions of average turnaround time limits on the $j$ th type of aircraft are less than 65 minutes for the first type of aircraft and less than 50 minutes for the second type of aircraft.

According to the above parameter settings about support process and support resources, the simulation model has been built using Arena14.0 and optimization procedure has been completed using OptQuest tool. In the simulation model, the length of each simulation run is considered as a training period of one week which consists of 7 days, $24 \mathrm{~h} /$ day, in total $148 \mathrm{~h}$. The number of independent replications for each run is 50. The result's confidence interval is $95 \%$. And because a steady-state analysis is needed to analyze a long time period, the warm-up period is decided as $2 \mathrm{~h}$.

Furthermore, the suggested, lower bound and higher bound values for the variables to be optimized need specification in OptQuest. The suggested values determine the starting point of the decision variables. The lower bound and higher bound values prescribe a limit to the search process. Affecting the efficiency and effectiveness of the search, all these values should be set based on the actual situation. If the reasonable values cannot be estimated in advance, the simulation analysts may run the optimization tool twice so that the current solution is used as suggested values in the second run in practice [16]. In this paper, the initial values are set according to one type of aircraft being supported, as shown in Table 2.

The output of optimization model is $X^{*}=(6,3,2,5,5,5,5,3)$ which is also shown in Table 3. The optimization results of average wait time are 0.0876 minutes for the first type of military aircraft and 0.0655 minutes for the second type of military aircraft, respectively. The sum of them is objective value $\min \sum_{\mathrm{j}=1}^{\mathrm{k}} \mathrm{T}_{\mathrm{wj}}\left(\mathrm{x}_{\mathrm{i}}\right)=0.1555$. The values of average 
maximum wait time are $3.4605,3.2846$ minutes, respectively. Under the initial values condition, the results of average wait time are 8.1664 minutes for the first type and 1.6168 minutes for the second type, respectively. The values of average maximum wait time are up to 30.7027 and 20.3133 minutes, respectively as shown in Table $\mathbf{3}$. This allocation is apparent inefficiency. However, under the plan values condition, the results of average wait time are 1.8984 minutes of the first type and 0.0269 minutes of the second type, respectively. The values of average maximum wait time are 14.1024 and 5.3926 minutes, respectively. More support resources are used and more average maximum wait time is spent than under the optimum values condition, so this allocation strategy should be improved in time.

\section{CONCLUSION}

The simulation model and optimum approach in this article address the problem of support resources allocation for MTMA in the support process. The support resources strategies are developed in the simulation model, especially when there are two or more types of support activities arranged to be performed in any order. The parameters and objective function are set easily according to the requirement of MTMA. The results of optimum allocation can be obtained in just a few minutes that can improve the efficiency of ground support activities of MTMA at an airport and increase the effectiveness of ground support resources. The simulation model and optimum approach are easily transferred to applied fields like the scheduling of mix production, flexible manufacturing and the multiple types of aircraft maintenance.

\section{CONFLICT OF INTEREST}

The author confirms that this article content has no conflict of interest.

\section{ACKNOWLEDGEMENTS}

The authors are grateful for the helpful discussion with Professor Q. Wang. The authors are thankful to the anonymous reviewers, whose thoughtful suggestions have greatly improved the article.

\section{REFERENCES}

[1] B. Xiong, Q. Z. Zhou, R. Fan, and D. Y. He, "Analysis and simulation based the design of multi-aircraft oil refilling system exploratory analysis method", Syst. Eng. Electron., vol. 35, pp. 1455-1459, July 2013.

[2] W. Dang and F. Che, "Battle damage spares demand model for multi-type aircraft based on campaign", Mathemat. Pract. Theory, vol. 42, pp. 148-154, January, 2013.

[3] D. L. Li, Z. J. Liu and Y. L. Wang, "Ammunition support capability for multi-type aircraft at air force station", J. Sichuan Ord., vol. 33, pp. 105-107, January, 2012.

[4] A. Mackenzie, J. O. Miller, R. R. Hill, S. P. Chambal, "Application of agent based modelling to aircraft maintenance manning and sortie generation", Simul. Modell. Pract. Theory, vol. 12, pp. 89-98, October, 2011.

[5] K. Iakovidis, "Comparing F-16 Maintenance Scheduling Philosophies", MS Thesis, School of Engineering and Management, Air Force Institute of Technology, Wright Patterson AFB, OH, U.S.A. June 2005.

[6] W. Yi, R. Kang and H. L. Cheng, "Calculation method for military aircraft's turnaround time", J. Beijing Univ. Aeronaut. Astronaut., vol. 34, pp. 1415-1418, December, 2008.

[7] D. C. Dietz and R C Jerkins, "Analysis of aircraft sortie generation with the use of a fork-join queuing network model", Naval Logist. Res., vol. 44, no. 2, pp. 153-164, March 1997.

[8] P.D. Faas, "Simulation of autonomic logistics system (ALS) sortie generation", MS Thesis, School of Engineering and Management, Air Force Institute of Technology, Wright Patterson AFB, OH, U.S.A. March 2003

[9] K. B. Pettinggill, "Analysis of the efficacy of the logistics composite model in estimating maintenance manpower productive capacity", Am. Air Force Inst. Technol., vol. 15, pp. 801-808, June, 2003.

[10] S. Q. Fang, K. Wei, W. P. Chen, S. H. Zhao and J. XU, "Modeling and simulation of flight support process of airfield station based on ARENA", J. Syst. Simulat., vol. 20, pp. 746-749, February, 2008.

[11] S. Q. Fang, K. Wei, W. P. Chen, S. H. Zhao and Y. Liu, "UML modeling and arena simulation of flight support process", Syst. Eng. Theory Pract., vol. 20, pp.165-169, November, 2008.

[12] F. Tian, Q. H. Xing and S. T. Wang, "Simulation and optimization of vehicle scheduling in flight logistic support process based on arena", In: Proc. Comput. Appl. Syst. Model. Int. Conf., pp. 446-449, 2010.

[13] X. M. Luo, Z. Y. Zhang, L. J. Xie, and H. J. Yang, "Simulation of four station equipment requirements among multi-aircraft support", Ord. Indust. Automat., vol. 28, pp. 45-48, September, 2009.

[14] W. D. Kelton, R. P. Sadowski and D. T. Sturrock, "Simulation with Arena", In: $5^{\text {th }}$ ed. New York: McGraw Hill Higher Education, 2009

[15] G. J. Han, H. X. Huang and X.Y. Luo, "New Air Logistics Staff Business Skills. FMl, Ji Nan: The Yellow Press, 2002.

[16] B. Y. Ekren and O. Ekren, "Simulation based size optimization of a PV wind hybrid energy conversion system with battery storage under various load and auxiliary energy conditions", Appl. Energy, vol. 86, pp. 1387-1394, February 2009. 